\section{Response to Daily}

SIR

I would like to thank Louis G Daily for his sympathetic and thoughtful comments. He is quite right that a 'Szaszian world' would not be a utopia, free of all 'abuse' of man by man. Assuming that in such a world all human relationships between competent adults would be consensual, and that the role of the State would be limited to punishing persons if they used force or fraud in their interaction with others, there would remain the possibility of Jones (badly informed or having bad values) giving bad advice to Smith which, were Smith to heed it, would injure him. This falls under the rubric of personal freedom, which is not the same as freedom from risk, but is indeed its opposite.

Separation of Church and State protects people only from institutionalized religious injury (the Inquisition); it offers no protection against the potentially self-injurious consequences of religious credulity (for example, believing that contraception is a sin). Mutatis mutandis, the separation of psychiatry and State would protect people only from institutionalized psychiatric injury (exemplified by the cases Daily cites, as he himself acknowledges); it would offer no protection against the potentially self-injurious consequences of psychiatric credulity (for example, believing that therapists can recover lost memories, as if memories were like car keys).

In concluding, Daily uses the phrase 'substandard science in psychiatry', implying that there is a standard science of psychiatry. I disagree. For nearly forty years I have argued that if the subject matter of psychiatry is how people live, how they might live, and how they ought to live, then psychiatry cannot be a science. In a comment on a recent article in The Economist, concerning the catastrophic state of mental health services in the UK, I concluded: 'So long as we refuse to view psychiatry as a branch of moral philosophy and law, and not as medicine, we cannot even begin to grapple with the problems [that psychiatry poses]' (1).

\section{Reference}

(1) Szasz T. In search of sanity [letter]. The economist 1995 Sept 30: 9-10 (cols 4, 1).
Department of Psychiatry, State University of New York, Health Science Center, 750 East Adams Street, New York 13210, USA

\section{Availability of organs}

SIR

The suggestion that it should be made widely known that you would have a better chance of receiving a transplanted organ if you had agreed to be an organ donor (1) is an instantly attractive one. Presumably it would increase the supply of this very scarce commodity. Raanan Gillon's 'major objection' - that it would introduce moral worthiness into the considerations that decide who gets a donated organ - leaves the supply of donated organs where it is, seriously inadequate. He says that doctors have obligations to try to provide medical benefits to all their patients who are in need; they would have a better chance of succeeding if more organs were available for transplant. Presumably there are many factors taken into account when deciding which of two needy patients gets the one available organ; willingness to be a donor could be one of them. It need not, as Dr Gillon implies, become the only criterion.

Would it not help if the general public knew what the present criteria are? It is a disquieting experience to be confronted at an international conference with statistical evidence that in Britain few people over fifty-five years old get kidney transplants, especially after having denied for years that this was the general policy.

\section{Reference}

(1) Jarvis R. Join the club: a modest proposal to increase availability of donor organs. Fournal of medical ethics 1995; 21: 199-204.

JEAN DAVIES

56 Marlborough Road, Oxford OX1 $4 L R$

PS With reference to the paper, Chinese Confucian culture and the medical ethical tradition, by Guo Zhaojiang, which was published in the August 1995 issue of the journal: The lectures I gave in Xian in 1992 were translated simultaneously into Chinese and the quotation from one of them, on page 245 , has suffered in the process - or possibly in the process of being translated back into
English. The point I was making was that two generations ago money was not a subject for polite conversation, then sex became something that was generally discussible, and now it is the turn of death to lose its taboo status.

\section{Evidence based medicine and ethics}

SIR

Tony Hope's editorial (1) on evidence based medicine prompted me along the following lines of thought. Evidence based medicine is, after all, what we should all want: not only would it get rid of 'received wisdom' (and any accompanying arrogance), but it might allow us with candour and surety to offer our patients the best possible treatments (given the current state of knowledge). And yet, there is something about evidence based medicine that is fishy. Is the feeling of fishiness a repressed Luddite inclination, or some other defensive mechanism against the possibility that the evidence might count against us? I think that there is more to the feeling of unease than the sensible qualms mentioned by Hope.

By the end of the editorial - in consequentialist mode - Hope considers the possibility that more empirical data (facts) might help in some ethical dilemmas. Some deontologists might wish to object to this along the lines of Wittgenstein's aphorism: 'You cannot lead people to what is good; you can only lead them to some place or other. The good is outside the space of facts' (2). Indeed, the is-ought question, whether and how you can move from a matter of fact to a matter of value, still remains taxing (3).

Earlier, however, Hope alluded to the thought that facts are seldom value-free. He will also be aware of Fulford's efforts 'to bring to the surface and out into the open the evaluative element in the conceptual structure of medicine' (4). One suggestion about the fishiness of evidence based medicine, then, is this: that there is a whiff of a reluctance to recognize the evaluative underpinnings of medicine. 'Evidence' suggests empirical evidence and a focus on facts not values.

I have also been struck recently by recommendations concerning the evaluation of outcome in mental health care: 'Studies should be comprehensive, to consider all the parameters on which an intervention 
should be effective; multiaxial, to consider the various views by which an intervention is considered effective; and specific, to consider the subjects and the conditions in which an intervention is effective' (5). These laudable suggestions raise for me the question whether actually we can provide such a comprehensive study of outcome. Ruggeri and Tansella (5) highlight the need to consider outcome (biological, psychological and social) from everyone's perspective. But what if those perspectives differ? What if a family and GP want an elderly person with dementia to be placed in a home, whilst the specialists and social services do not (or vice versa)? What evidence will then count? Some facts will seem pertinent, no doubt; but perhaps different facts to different families or different specialists. And what is pertinent seems like an evaluation: the facts (the evidence) will not always decide the matter.

This thought, emphasizing the importance of judgments of value, can only be circumvented - it seems to me - by the claim that (at least potentially) we can know all the facts and when we do there will be no issues of value to interfere with the evidence. I think that this is why evidence based medicine seems fishy, for it holds out the promise of a perfect clinical science. The corollary is that it threatens anything which we feel is not amenable to scientific scrutiny.

Nevertheless, since all that can be scrutinized scientifically should be, this is not to take a stance against evidence based medicine. It is, however, to note that there is more to medicine than the physical. Now, to some, talk of meta-physics will seem Luddite. But I should have thought that the exclusion of metaphysics from medicine would ensure the death of medical ethics as a discipline concerned with (specifically) moral values.

\section{References}

(1) Hope T. Evidence based medicine and ethics [editorial]. fournal of medical ethics 1995; 21: 259-260.

(2) Wittgenstein L. Culture and value [2nd ed]. Oxford: Basil Blackwell, 1978: $3 \mathrm{e}$.

(3) Hudson W D, ed. The is-ought question. A collection of papers on the central problem in moral philosophy. London and Basingstoke: The Macmillan Press, 1969.

(4) Fulford K W M. Moral theory and medical practice. Cambridge: Cambridge University Press, 1989: 173.

(5) Ruggeri $M$, Tansella $M$. Evaluating outcome in mental health care. Current opinion in psychiatry 1995; 8: 116-121.

\section{JULIAN C HUGHES Warneford Hospital, Oxford, England}

\section{Evidence based medical ethics}

\section{SIR}

As Hope discussed in his editorial (1), evidence based medicine is now fashionable. The main principle, hardly new, is that clinical decisions and procedures, for care, comfort or cure, should be based on the best available evidence, founded whenever possible on randomized clinical trials, and not applied just because they are received wisdom. Hope briefly raises an example where medical ethics might benefit from such an approach. Is keeping information about an epileptic driver from the licensing authority less or more helpful to other road users at possible risk, than breaking the principle of confidentiality without consent would be in deterring other epileptic drivers from seeking medical advice? However, he does not discuss the logical next step which is to propose a method of seeking evidence to try and clarify this particular ethical problem. A parallel problem of balancing confidentiality against possible harm to others, much discussed at present, is the desirability of unknowing consorts of HIVpositive subjects being informed of the risks that they run.

I take the example of informed consent to surgery - though I prefer the term valid consent, as merely informing is often not sufficient for adequate understanding. In our current rightsbased society it is now taken as axiomatic that the doctor has the responsibility to inform the patient, who as an autonomous person has the right to know and understand all possible benefits and hazards of the procedure. This applies even if patients may not want the worry of knowing everything, but consider that their autonomy, value as persons, and freedom of choice are sufficiently respected by being given the basic information. But going through the full procedure of obtaining and checking such valid consent, with detailed explanations, takes much time and effort that could be devoted to other patients. My argument is that we have no evidence; this procedure does not fit with evidence based medicine; we do not know whether the consenting patient actually benefits, except philosophically. A utilitarian approach can be taken, that the benefit to the consenting patient is outweighed by the lessened opportunity of care for others.

No doubt it is a generation too late to do a controlled trial: patients who expressly wish only for basic information, or for full information and explanation, would be excluded in the same way as in a clinical trial. Randomized patients will either be subjected to the full consent procedure, or be treated as Sir Lancelot Spratt treated them when I was a student 50 years ago 'What do you mean, you now want to. know all about how I do the amputa tion and every possible hazard. You trusted me enough to come to my outpatients when I told you the choices and you agreed to surgery, so you can rely on me to do what is best for you'. 'Of course doctor, I leave it to you'. 'Seven o'clock in the morning'. One could then measure if there were any difference in mortality, morbidity, and happiness between the groups; and be able to balance this against the time and opportunity gained by not going through the full consent procedure. If this approach is Politically Incorrect the deontology thought police and rights activists will get you (presumably in these columns) if you don't watch out - then perhaps we could work out a thought experiment as done by the cosmologists. What if ...?

\section{Reference}

(1) Hope T. Evidence based medicine and ethics. Fournal of medical ethics 1995; 21: 259-260.

D N BARON, MD DSc 47 Holne Chase, London N2 OQG 